\title{
Los personajes fugitivos de las adaptaciones cinematográficas de Tennessee Williams: Dulce pájaro de juventud (Richard Brooks, 1962) y la crisis del Código Hays
}

Tennessee Williamsen egokitzapen zinematografikoetako pertsonaia iheslariak: Gaztaroko txori eztia (Richard Brooks, 1962) eta Hays kodearen krisia Fugitives Characters in the Tennessee Williams Films: Sweet Bird of Youth (Richard Brooks, 1962) and the crisis of the Hays Code

\author{
Valeriano Durán Manso \\ Universidad de Cádiz
}

\begin{abstract}
RESUMEN: La construcción del personaje es uno de los principales rasgos de uno de los escritores más adaptados del cine clásico, Tennessee Williams. Marcados por el universo sureño, sus personajes se agrupan en damas al límite, jóvenes atormentados, progenitores dominantes, integrados en la vida y fugitivos, el más numeroso. Con el objetivo de tratar su impacto en un Hollywood determinado por el Código Hays, se analizan como persona y como rol los fugitivos del filme Dulce pájaro de juventud (Richard Brooks, 1962), quienes, además, representaron tres temas condenados por el código que propiciaron su crisis: la drogadicción, la prostitución y el aborto.
\end{abstract}

PALABRAS CLAVE: personaje, historia del cine, Hollywood, censura, melodrama.

ABSTRACT: The construction of the character is one of the main traits of one of the most adaptated writers of classic cinema, Tennessee Williams. Marked by the southern universe, his characters are grouped in ladies to the limit, tormented young, dominant parents, integrated in life and fugitives, the most numerous. With the aim of treating its impact in a Hollywood determined by the Hays Code, the fugitives of the film Sweet Bird of Youth (Richard Brooks, 1962) are analyzed as a person and as a role. They also represented three topics condemned by the code that propitiated their crisis: drug addiction, prostitution and abortion.

KEYWORDS: character, history of cinema, Hollywood, censorship, melodrama.

\footnotetext{
* Correspondencia a / Corresponding author: Valeriano Durán Manso. Departamento de Marketing y Comunicación. Facultad de Ciencias Sociales y de la Comunicación. Universidad de Cádiz. España. Avenida de la Universidad s/n (11405 Jerez de la Frontera-Cádiz). España - valeriano.duran@uca.es - https://orcid.org/0000-0001-9188-6166

Cómo citar / How to cite: Durán Manso, Valeriano (2020). «Los personajes fugitivos de las adaptaciones cinematográficas de Tennessee Williams: Dulce pájaro de juventud (Richard Brooks, 1962) y la crisis del Código Haysu, Zer, 25(48), 127-146. (https://doi.org/10.1387/zer.21347).

Recibido: 22 diciembre, 2019; aceptado: 03 abril, 2020.

ISSN 1137-1102 - eISSN 1989-631X / (c) 2020 UPV/EHU

(c) Esta obra está bajo una licencia
} 


\section{Introducción}

La producción del dramaturgo norteamericano Tennessee Williams es una de las más adaptadas en el Hollywood clásico. El universo literario del autor experimentó un gran éxito en Broadway entre las décadas de los 40 y de los 60, y, por esta razón, no tardó en llamar la atención de diversos productores y cineastas en los 50. Emocionalmente ligado al origen sureño de su familia, tuvo en este espacio una de las principales fuentes de inspiración para el desarrollo de su obra literaria (Holditch and Freeman Leavitt, 2010). Así se evidenció en los temas y personajes que protagonizaron sus escritos, quienes eran víctimas de las circunstancias, problemas y deseos que él mismo tenía, y que, además, eran un reflejo de sus familiares más cercanos: su madre, Edwina; su hermana, Rose; y su abuelo, el reverendo Walter Dakin, que "was a kindly, gentle, affectionate book lover who became the most important male figure in their life. Rose and Tom flourished in the loving parochial environmental of their grandfather's rectory» (Smith-Howard and Heintzelman, 2005: 4). El zoo de cristal (The Glass Menagerie) fue la obra donde estas premisas quedaron más patentes — e incluso la ausencia de su padre-, una memory play que fue adaptada en 1950 por Irving Rapper y que supuso su primera incursión filmica, con Gertrude Lawrence, Arthur Kennedy y Jane Wyman en los roles de Amanda, Tom y Laura Wingfield, inspirados en Edwina, el autor y Rose. Resulta necesario conocer el contexto familiar de Williams para comprender su producción, pues, como asegura Phillips, «a writer's life is his work and his work is his life» (1980: 38).

Las circunstancias familiares y personales determinaron el carácter del escritor, quien se convirtió en un fugitivo de su propia realidad debido a su carácter solitario, su espíritu errante y su condición homosexual (Williams, 2008). Esto se reflejó en su tendencia por crear personajes que tienen que huir - bien a nivel fisico o psicológico-, de un entorno hostil, de la incomprensión o de sí mismos. En los escenarios de Broadway estos seres de ficción tuvieron un éxito que se topó en el cine con la hegemonía del Código Hays, el sistema de censura que desde 1934 dominaba la producción de Hollywood (Black, 1998). La combinación de aspectos complejos y personajes controvertidos se puso de relieve especialmente en la segunda adaptación de Williams, Un tranvía llamado deseo (A Streetcar Named Desire), que, realizada por Elia Kazan en 1951 - tras dirigirla sobre las tablas en 1947-, trataba temas condenados como el alcoholismo, la ninfomanía y la violación. A partir de aquí, sus dramas despertaron gran interés en la industria, aunque sufrieron las imposiciones del sistema para estrenarse. A pesar de ello, la aparición de estas adaptaciones fue coincidiendo con el aperturismo que experimentó el código hasta 1967, cuando fue sustituido por un sistema de calificación por edades.

Dulce pájaro de juventud (Sweet Bird of Youth, Richard Brooks, 1962) es una de las películas que evidencian la unión de temas complejos y personajes fugitivos en 
el marco de la crisis del Código Hays. Sus protagonistas, Chance Wayne, Alexandra del Lago y Heavenly Finley - encarnados por Paul Newman, Geraldine Page y Shirley Knight-, son víctimas de unas realidades personales, familiares, sociales o sexuales que los obligan a tener que huir para ser felices. Además, representan, respectivamente, y en un mismo filme, tres temas prohibidos por la censura: la prostitución, la drogadicción y el aborto. Se trata de unos seres de ficción con orígenes, contextos y aspiraciones muy diversas, que comparten el universo frágil y atormentado del dramaturgo.

Esta adaptación es la primera realizada sobre la obra de Williams y pertenece al periodo comprendido entre 1950 y 1968, en el que doce dramas y una novela fueron adaptados en Hollywood: El zoo de cristal, Un tranvía llamado deseo, La rosa tatuada (The Rose Tattoo, Daniel Mann, 1955), Baby Doll (Baby Doll, Kazan, 1956), La gata sobre el tejado de zinc (Cat on a Hot Tin Roof, Brooks, 1958), De repente... el último verano (Suddenly, Last Summer, Joseph L. Mankiewicz, 1959), Piel de serpiente (The Fugitive Kind, Sidney Lumet, 1960), Verano y humo (Summer and Smoke, Peter Glenville, 1961), La primavera romana de la señora Stone (The Roman Spring of Mrs. Stone, José Quintero, 1961), Dulce pájaro de juventud, La noche de la iguana (The Night of the Iguana, John Huston, 1964), Propiedad condenada (This Property Is Condemned, Sydney Pollack, 1966), y La mujer maldita (Boom!, Joseph Losey, 1968). Asimismo, pertenece al melodrama, un género narrativo de marcado carácter popular que favorece el proceso de identificación de los espectadores con los personajes.

\section{Objetivos y metodología}

El presente trabajo parte de la hipótesis de que las adaptaciones de Tennessee Williams han tenido un importante papel en el aperturismo temático del Hollywood clásico y en el final del Código Hays. Teniendo en cuenta que los personajes del autor ocupan un rol esencial en el desarrollo de sus obras y de sus películas, se plantean estos objetivos:

- Reflexionar sobre las aportaciones de Williams en el cine clásico.

- Realizar una aproximación al tratamiento de sus personajes fugitivos en la pantalla, en una época marcada por el debilitamiento del Código Hays.

- Analizar como persona y como rol a los protagonistas de Dulce pájaro de juventud, Chance Wayne, Alexandra del Lago y Heavenly Finley.

Para ello, se ha empleado una metodología cualitativo-descriptiva. En primer lugar, se ha revisado la obra original — publicada en 1959-, para profundizar en la adaptación que Brooks dirigió en 1962. Dulce pájaro de juventud se estrenó durante la crisis estructural que atravesaba Hollywood, trataba aspectos prohibidos por el Código Hays y mostraba personajes inéditos y de gran complejidad interna. 
Por ello, resulta una película bastante representativa del impacto que las adaptaciones de Williams tuvieron en el Hollywood posterior a la II Guerra Mundial (Palmer y Bray, 2009), tanto por sus temas como por sus seres de ficción. Así, el corpus de análisis está centrado en sus tres protagonistas, en los que el carácter fugitivo es fundamental en su evolución.

\begin{tabular}{|c|c|c|c|}
\hline & Chance Wayne & Alexandra del Lago & Heavenly Finley \\
\hline \multicolumn{4}{|c|}{ Iconografia } \\
\hline \multicolumn{4}{|l|}{ Edad } \\
\hline \multicolumn{4}{|l|}{ Apariencia } \\
\hline \multicolumn{4}{|l|}{ Vestuario } \\
\hline \multicolumn{4}{|l|}{ Habla } \\
\hline \multicolumn{4}{|c|}{ Transformación } \\
\hline \multicolumn{4}{|c|}{ Psicología } \\
\hline \multicolumn{4}{|l|}{ Carácter } \\
\hline \multicolumn{4}{|c|}{ Relatión con los demás } \\
\hline \multicolumn{4}{|l|}{ Pensamiento } \\
\hline \multicolumn{4}{|l|}{ Sentimientos } \\
\hline \multicolumn{4}{|l|}{ Evolución } \\
\hline \multicolumn{4}{|c|}{ Sociología } \\
\hline \multicolumn{4}{|l|}{ Nivel social } \\
\hline \multicolumn{4}{|c|}{ Nivel económico } \\
\hline \multicolumn{4}{|l|}{ Nivel cultural } \\
\hline \multicolumn{4}{|c|}{ Sexualidad } \\
\hline \multicolumn{4}{|l|}{ Género } \\
\hline \multicolumn{4}{|c|}{ Orientación sexual } \\
\hline \multicolumn{4}{|c|}{ Rol } \\
\hline \multicolumn{4}{|l|}{ Tipo } \\
\hline \multicolumn{4}{|l|}{ Motivaciones } \\
\hline Acciones & & & \\
\hline
\end{tabular}

Fuente: Grupo Admira basado en Casetti y Di Chio.

GRÁFICO 1

Plantilla de análisis de personajes como persona y como rol 
En segundo lugar, se han consultado artículos, biografias, y libros de correspondencias de especialistas en Williams, como Paller (2014), Holditch y Freeman Leavitt (2010), Smith-Howard y Heintzelman (2005), Devlin y Tischler (2004), Spoto (1985) o Steen (1969), además de textos sobre la producción filmica del autor, como los de Palmer (2014; 1997), Palmer y Bray (2009), Hooper (2014), Phillips (1980) o Yacowar (1977). Por otra parte, se ha abordado la construcción del personaje audiovisual a través de autores como Casetti y Di Chio (2007), y de sus personajes en el cine, mediante Durán Manso $(2015 ; 2011)$ y Clum (1997). Para conocer el contexto en el que las adaptaciones se rodaron, se han revisado trabajos en torno al Código Hays (Rodríguez de Austria Giménez de Aragón, 2015; Palmer y Bray, 2009; Black, 1998), Richard Brooks (Casas e Iriarte, 2009) y el Actor's Studio (Frome, 2001). Asimismo, las memorias de Williams (2008) han sido de especial relevancia para la investigación.

En tercer lugar, se ha analizado a los protagonistas de la película como persona y como rol según la herramienta de análisis de personajes creada por el grupo de investigación en Análisis de Medios, Imágenes y Relatos Audiovisuales (AdMIRA) de la Universidad de Sevilla, según las teorías de Casetti y Di Chio. Se trata de una herramienta cualitativa que permite conocer la dimensión iconográfica —edad, apariencia, habla—, psicológica — carácter, forma de relacionarse con los demás, pensamientos, sentimientos y evolución-, sociológica — niveles social, económico y cultural一, o la sexualidad, del personaje como persona, así como las motivaciones y acciones, en cuanto al rol. Esta plantilla pretende evidenciar la creación de los personajes como seres próximos a la vida real.

\section{Marco teórico: el universo de Williams}

\subsection{De Broadway a Hollywood: éxito y melodrama}

El universo literario de Williams tuvo un importante éxito en Broadway en la década de los 40. Su primera gran obra, El zoo de cristal, se estrenó en 1944 y reflejaba su propia vida, la de su madre y la de Rose cuando era un adolescente y vivían de forma precaria en San Luis con la ausencia de su progenitor. Este éxito le otorgó un destacado lugar en la escena neoyorquina que se reforzó con el estreno de Un tranvía llamado deseo. Este drama logró el premio Pulitzer y también el New York Drama Critic's Circle Award y el Donaldson, que El zoo de cristal había conseguido tres años antes. Ambos montajes llamaron la atención de productores y de directores de Hollywood, como Elia Kazan o Richard Broks, debido a la situación que la industria cinematográfica atravesaba tras la II Guerra Mundial. Hollywood tenía tres problemas que estaban alterando el sistema de producción: la crisis del sistema estudios, el auge de la televisión y la Caza de brujas del senador Joseph McCarthy (Palmer y Bray, 2009; Black, 1998). Este contexto propició que se adaptaran los prin- 
cipales éxitos de Broadway — pues la escena gozaba de mayor libertad temática-, para recuperar a los espectadores y realizar películas más próximas a la sociedad. La idea chocaba con el Production Code Administration (PCA) - conocido como Código Hays por el nombre de su impulsor, William Harrison Hays, el presidente de la Motion Picture Producers and Distributors of America (MPPDA) - , que desde 1934 condenaba los filmes que tenían aspectos sexuales o considerados amorales (Rodríguez de Austria Giménez de Aragón, 2015; Black, 1998), pero resultaba oportuno abordar algunos como el adulterio, el alcoholismo, la drogadicción, las relaciones interraciales o la homosexualidad. Además, la mayoría no se trataban en las películas desde el periodo Pre-code (1930-1934), ante el temor de que constituyeran un modelo perverso para la sociedad. Por ello, esta norma censora tuvo el apoyo de la Iglesia Católica y contó en su redacción con el editor católico Martin Quigley y el jesuita Daniel Lord.

Desde el principio, las adaptaciones del dramaturgo tuvieron problemas con el código. Así, en Un tranvía llamado deseo Kazan «necessarily removes, or represents differently, the three areas of the play that troubled Hollywood's Production Code Administration (PCA): namely, Allan Grey's homosexuality, Blanche's history of promiscuity and the rape» (Hooper, 2014: 353). A partir de aquí, las películas de Williams padecieron los estragos de la censura hasta finales de los 60, debido a sus controvertidos temas y sus atormentados personajes. Considerado «enfant terrible of post-war Broadway» (Palmer, 2014: 111), el autor destacó en el Hollywood de los 50 con unas adaptaciones en las que expresaba el convervadurismo de la actual sociedad sureña y del American way of life, como Un tranvía llamado deseo, La rosa tatuada, Baby Doll, La gata sobre el tejado de zinc o De repente... el último verano:

Hollywood producers found the Williams properties attractive precisely because they treated time-honored subjects upon whose appeal the film industry had long depended. These included the ravaging effects of time on human destiny; the irregular passages of romantic life, marked by betrayal, loss and compromise; the moral and psychological discontents of sexual desire as lived out in a society with a long history of repressive attitude, the unavoidable tensions of intimate relationships; and -in a more specifically national vein - the exotic, fascinatingly perverse nature of southern culture. (Palmer, 2014: 111-112)

Estos aspectos temáticos se plasmaron en los personajes de Williams, determinando la aparición de un nuevo prototipo en Hollywood, más complejo a nivel psicológico y más próximo al individuo. En este sentido, el Actor's Studio ejerció un significativo papel en el desarrollo de los personajes del autor y en el éxito de sus adaptaciones. Fundado en 1947, se convirtió en una de las principales canteras de actores por sus técnicas basadas en el método de Stanislavski (Frome, 2001), quien creó un nuevo estilo escénico y una fórmula de actuación que propiciaba la inmer- 
sión en el personaje. Además, cada actor debía crear un estímulo interno próximo al ser de ficción y usar la memoria emotiva, es decir, ir a los recuerdos para hallar en el pasado situaciones análogas a las que vive el personaje. Esto tuvo una gran influencia en el teatro contemporáneo y contribuyó a que los actores proyectaran emociones reales a sus personajes. Así se percibe en alumnos - y después estrellas - como Marlon Brando, Montgomery Clift, Paul Newman, Geraldine Page, Karl Malden, Carroll Baker o Eli Wallach (Frome, 2001), quienes actuaron en obras y filmes de Williams. Algunos comenzaron sus carreras encarnando a sus seres de ficción, como le ocurrió a Brando en Un tranvía llamado deseo. De esta manera, "his characters, in turn, could only be fully realized by a different kind of naturalistic acting capable of representing conflicted, multilayered selves: the so-called 'Method' that had recently come into vogue the founding of the Actor's Studio" (Palmer, 1997: 207).

Los filmes de Williams contribuyeron a la evolución de Hollywood hacia un cine más adulto (Palmer y Bray, 2009), pero también al desarrollo del melodrama como género narrativo, que giró hacia aspectos más reales y hasta sórdidos. En este sentido, ocuparon un prominente lugar en el cine clásico realizado durante estos años, y participaron en la disolución del Código Hays, aunque sufrieron sus secuelas debido a la carga sexual. Así sucedió en las citadas Un tranvía llamado deseo, Baby Doll y La gata sobre el tejado de zinc, aunque la habilidad de Kazan en los dos primeros casos y de Brooks en el último posibilitaron que se percibieran varios de los asuntos planteados, como la ninfomanía, el adulterio o la homosexualidad, respectivamente. En un momento en el que Hollywood se dirigía hacía el tratamiento de temas más adultos, el género experimentó una notable evolución con títulos que constituyeron «algunos de los melodramas más relevantes que se realizaron en Hollywood en las décadas de los 50 y 60» (Durán Manso, 2015: 683). Además, influyeron en otros importantes melodramas basados en éxitos de Broadway de dramaturgos contemporáneos a Williams — como Picnic (Picnic, Joshua Logan, 1955) y Esplendor en la hierba (Splendor in the Grass, Kazan, 1961), de William Inge, o Té y simpatía (Tea and Sympathy, Vincente Minnelli, 1956), de Robert Anderson-, quienes abordaban también aspectos condenados por el código.

\subsection{Temas esenciales y tipología de Personajes}

Una de las principales señas de identidad de Williams es el planteamiento de temas de carácter controvertido como la violación, la ninfomanía, el adulterio, la homosexualidad, el alcoholismo, la prostitución, la drogadicción, el aborto o el deseo - todos prohibidos por el código-, que, a su vez, pueden organizarse en estos tres ejes temáticos: el miedo, el sexo y el Old South (Durán Manso, 2011). El primero aparece unido a la soledad y el fracaso, y refleja el frágil y vulnerable universo de los protagonistas. Muchos de ellos se refugian en el alcohol, las drogas, el sexo o la represión para intentar sobrevivir en un contexto social, familiar o personal adverso. En al- 
gunas ocasiones, el miedo representa una cárcel para los seres williamsianos. Normalmente, el segundo aparece en los filmes a través de la dicotomía entre la represión y la liberación sexual, y se representa en el deseo, la no aceptación de la sexualidad, la homosexualidad o la prostitución. Además, los personajes masculinos suelen sufrir rechazo personal y social si su orientación no es heterosexual, mientras que los femeninos son rechazados si su actitud en el sexo no es recatada. A este respecto, el escritor critica el puritanismo que defiende en el sexo unas actitudes específicas dependiendo del género. Por último, el Old South - y su recuerdo-, determina el conflicto entre el glorioso pasado y el dificil presente de los protagonistas. Esta dicotomía afecta sobre todo a unos femeninos que tras perder su patrimonio tienen que adaptarse al ruinoso sur heredero del Old South. Así, la obra de Williams «occur in a world of insensitivity, brutality and violence. In it, we often witness, to recall [Harold] Pinter's phrase, "the destruction of an individual"”(Paller, 2014: 285).

Otro de los rasgos esenciales del autor es la construcción de unos seres de ficción de gran complejidad dramática, y, a la vez, próximos a la realidad de los individuos. Esto revela la habilidad de Williams para profundizar en el estudio del alma humana, y, en definitiva, la suya, debido al paralelismo entre su vida y su obra que se revela en unos protagonistas que a veces funcionan como su alter ego (Williams, 2008). Sus personajes se pueden articular en las siguientes categorías (Durán Manso, 2011):

- Damas al límite. El dramaturgo se inspiró en su madre para crear unas mujeres sureñas que presenta como herederas de las plantaciones de las familias del Old South. Tras la Guerra de Secesión y la pérdida de los valores del sur, se aferran a la opulencia en que vivieron, pero se pierden en una nueva sociedad que no las comprende y que tampoco quieren entender. Son mujeres que se enfrentan a la madurez con carisma y belleza, pero que poseen una naturaleza extremadamente vulnerable. Los principales ejemplos son Amanda Wingfield y Blanche DuBois, las protagonistas de El zoo de cristal y de Un tranvía llamado deseo, quienes son incapaces de adaptarse a la vida de San Luis y de Nueva Orleans.

- Jóvenes atormentados. Estos personajes, que tienen belleza física y una edad comprendida entre los 18 y los 30 años, suelen refugiarse en su propio universo por problemas personales, sentimentales o familiares que les impiden ser felices. Además, viven en sociedades puritanas que continuamente cuestionan sus ansias de libertad. Por ello, están marcados por el conflicto entre individuo y sociedad, y, aunque encarnan conflictos universales comunes a los jóvenes, poseen una existencia trágica. Los casos más representativos son los de Brick Pollit y Alva Starr, protagonistas de La gata sobre el tejado de zinc y Propiedad condenada.

- Progenitores dominantes. Este prototipo supone el contrapunto a los anteriores y, a menudo, encarna la prisión en la que se encuentran. Se trata 
de personajes autoritarios, represivos e incapaces de empatizar con quienes piensan de manera diferente o son sensibles. Han luchado para lograr o mantener el elevado estatus que poseen y están preocupados en proporcionar a sus hijos una vida cómoda a nivel económico, pero no a nivel emocional. Los patriarcas de La gata sobre el tejado de zinc, Big Daddy, y Dulce pájaro de juventud, Boss Finley, y la madre de De repente... el último verano, Violet Venable, son los más relevantes.

- Integrados en la vida. Estos personajes sobreviven aceptando su presente - que no siempre es el que prefieren-, y así encuentran la manera de ser felices. Son conscientes de que tienen que luchar para salir adelante, y, como no han perdido nada al carecer de un pasado glorioso, son más positivos y valientes. Funcionan en las películas como contrapunto a los seres de ficción de las demás categorías, especialmente los atormentados y los fugitivos. Los personajes de Un tranvía llamado deseo, La gata sobre el tejado de zinc o La noche de la iguana, Stanley Kowalski, Maggie Pollit y Maxine Falk, se enmarcan aquí.

- Fugitivos. Los personajes de esta categoría — la más numerosa-, están sin rumbo debido a la complicada situación personal o profesional que atraviesan. El miedo al fracaso o la soledad los tiene dominados y no encuentran sentido a sus vidas. Estos personajes suelen evadirse a través del alcohol, las drogas o el sexo, pero, realmente, estas fórmulas no solucionan la espiral de autodestrucción que los va ahogando. Por ello, son solitarios y tienen un estado emocional inestable, a pesar de que a veces gozan de una interesante vida social. El mejor ejemplo es Karen Stone, la protagonista de La primavera romana de la señora Stone, quien, tras un fracaso teatral, se hunde en una deriva vital que la lleva a sentir que flota en el vacío. Además, los protagonistas de Dulce pájaro de juventud, Alexandra, Chance y Heavenly, pertenecen a este grupo, pues, aunque presentan rasgos de los jóvenes atormentados, se hallan en una continua huida de sí mismos al sufrir, respectivamente, el rechazo profesional, el social y el familiar.

\section{Análisis: Dulce pájaro de juventud (Richard Brooks, 1962)}

\subsection{Adaptación y CONTEXto hollywoodiense}

Tras el reciente éxito de las adaptaciones cinematográficas de La gata sobre el tejado de zinc (1958) y De repente... el último verano (1959), que abordaban, respectivamente, la homosexualidad, el alcoholismo y el adulterio, y la homosexualidad, el canibalismo y el complejo de Edipo, Hollywood se interesó por llevar a la pantalla un texto de Williams que había obtenido un reciente éxito en Broadway, Dulce pájaro de juventud. Esta obra poseía aspectos totalmente opuestos a las indicaciones del Código Hays (Black, 1998), pero que resultaban muy interesantes en el Hollywood de 
principios de los años 60 para recuperar al público perdido por la televisión. Los temas que el escritor plasmó fueron, en primer lugar, las ilusiones perdidas, a pesar de la juventud de los protagonistas, y, en segundo lugar, la ambición personal, social, familiar, profesional o política sin límites. Asimismo, el miedo a la soledad indica la fragilidad emocional de los personajes, y esta vulnerabilidad los lleva a refugiarse en varias adicciones. En este contexto, dos temas tradicionalmente condenados por el código, y que a finales de los 50 experimentaron un cierto aperturismo, empezaron a tratarse en el cine: la drogadicción y la prostitución. Chance y Alexandra consumen hachís, él trabaja como su gigoló, y, además, otro tema tabú, el aborto, aparece como reflejo de la conservadora sociedad sureña heredera del Old South, que es mostrada como excesivamente hipócrita y únicamente preocupada por la moral, el estatus y mantener las apariencias. Por este motivo, se puede afirmar que esta adaptación fue bastante audaz para su tiempo:

The Williams films helped usher in a form of American filmmaking that was unabashedly literary and unconcerned with glamour, glitz and action and no longer carried along by a simplistic and easily readable narrative; they were also striking in being less afraid of offending traditional pieties $[\ldots]$. And yet this adultness was striking only from an American perspective because the Williams films were, stylistically speaking, hardly provocative or influential beyond national borders, even though made by an honor roll of postwar directors that included such luminaries [...] as Elia Kazan, John Huston, Daniel Mann and Richard Brooks. (Palmer, 2014: 123-124)

Williams escribió la obra basándose en ciertos aspectos y personajes de varias de sus obras en un solo acto, The Purification (1940), The Big Time Operators (1948) y The Enemy, Time (1952). Antes de su estreno en Broadway, el autor le confesó a su agente teatral, Audrey Wood, que este trabajo podía ser «the strongest play I have written», a lo que añadió que «it will have a great impact as theatre» (Devlin y Tischler, 2004: 605-606). Después de su experiencia en las producciones teatrales de La rosa tatuada (1951) y de Camino Real (1953), Cheryl Crawford se enfrentó al montaje de Dulce pájaro de juventud en 1959, contando con Brooks en la dirección y con Paul Newman y Geraldine Page como protagonistas, a pesar de que Williams prefería a Marlon Brando en el papel de Chance. El éxito de La gata sobre el tejado de zinc empujó a Metro Goldwyn Mayer a querer lograr otro triunfo similar de taquilla. Sin embargo, el estudio veía necesario realizar cambios para tener una historia menos violenta y más próxima al melodrama familiar. A este respecto, Yacowar reconoce que «the producers were attracted to the sensational values of the play, but lacked the courage to present them as found. So the play was completely subverted» (1977: 93). Asimismo, algunos de los temas esenciales de la obra se redujeron para enfatizar la relación sentimental y los conflictos personales de los personajes, aunque Brooks consiguió que se percibieran. 
Las principales modificaciones realizadas por el cineasta afectaron a la estructura y a los seres de ficción. La más significativa se plasmó en la sustitución del demoledor final de la obra por un happy end impuesto por los productores, con el objetivo de dar esperanza a los protagonistas y satisfacer los intereses melodramáticos de uno de los estudios más conservadores de Hollywood. Por otra parte, y como había sucedido con la adaptación de De repente... el último verano, Brooks incorporó varios fashbacks mediante el uso de la pantalla dividida en las secuencias en las que los personajes recordaban su pasado, en lugar de mantener sus diálogos originales. Con ello, se reducía el carácter teatral que podía tener el filme. En cuanto a los protagonistas, el director humanizó a Chance al mostrar su dolor por la pérdida de su madre y su amor por Heavenly, personaje que fue más desarrollado para ofrecer una mayor dimensión a los sentimientos de éste. Por ello, se incluyó una reunión entre ambos a través de un flashback cuando esto no sucedía en el drama original. En cuanto a Alexandra, Brooks apostó por acentuar su imagen más interesada, pues solo ayuda a Chance cuando está amenazada.

Por otra parte, también reforzó la faceta política de Boss Finley con la incorporación de una escena que reflejaba su forma fraudulenta de actuar para obtener votos, presionando al alcalde, al jefe de policía y al editor del periódico después de escuchar las críticas de su oponente liberal. Así, el cineasta «supplies a fuller social canvas behind the action, perhaps correcting what even Williams took to be a fault in the play, a strained social background» (Yacowar, 1977: 96). Otros dos aspectos vinculados con la sexualidad que suponían un ataque al código también fueron cambiados en el filme. Así, la enfermedad venérea que Chance transmitía a Heavenly fue reemplazada por un embarazo que, al no estar casada, terminó en aborto, y la castración del protagonista fue sustituida por una brutal paliza que le desfiguraba el rostro, su arma para triunfar en Hollywood:

For a 1962 American movie, this may have been brave, but an important metaphor is lost in the translation. For Williams's Chance Wayne contaminated Heavenly with his own prostitution. His «profession» of love has poisoned even his idyllic love-making, so that now he can only implant poison and sterility. But in the film Chance can still plant life; sadly, the industry was not mature enough to present a star like Newman in a role so harshly drawn. (Yacowar, 1977: 95)

Muchas de estas alteraciones se recogieron en la memoria de la PCA sobre los aspectos que la película debía cambiar. Aunque a principios de los 60 esta institución estaba más debilitada, estableció cinco recomendaciones: excluir insinuaciones sobre la ninfomanía de Alexandra; eliminar alusiones sobre el tipo de relación existente entre Chance y ella; reemplazar la enfermedad venérea de Heavenly por una operación ilegal, que aludía a un aborto que sucedía en contra de su voluntad antes del inicio de la trama; eliminar la castración; y aclarar que la aventura que los jóvenes tuvieron 
en el pasado se produjo por la negativa de Boss a que se casaran. Estas sugerencias se reflejaron en el guion y, al final, el filme obtuvo la aprobación de la PCA y de la Legión Católica de la Decencia - organización afín que velaba por la moral en el cine (Black, 1998) — , para estrenarse. No obstante, Newman y Page plasmaron el sentido trágico del autor, pues «too often the characters are the author's mouthpieces, speaking not from their own inner logic and wholeness, but out of the author's own anger and frustration, with an inappropriately poetic reflectiveness» (Spoto, 1985: 321). La adaptación alteró la clave principal de la obra, es decir, que «youth, sex and vitality are destroyed both by the natural process of age and by the unnatural viciousness of man» (Yacowar, 1977: 93-94), y, en cambio, declaró que «the sweet bird of youth and innocence has not flown away; it has been caught and caged» (1977: 96). A pesar de este cambio, se trata de una de las películas favoritas del escritor, quien admitió que el guion "was an improvement on the play» y que "the film itself was more enjoyable than seeing the play» (Steen, 1969: 227).

\subsection{ANÁLISIS DE PERSONAJES}

Dulce pájaro de juventud transcurre en la ciudad costera de Saint Cloud, en Mississippi. Al Hotel Regal Plams llegan Chance Wayne y Alexandra del Lago, un aspirante a actor y una estrella en crisis. Ambos se refugian en la suite y hablan de la destrucción en la que viven. La prostitución, el chantaje y la droga definen la relación de conveniencia que mantienen, a pesar de la admiración que despiertan por vivir en Hollywood. Allí se encuentran con Heavenly Finley, la novia de Chance, una joven marcada por la política caciquil de su padre, la manipulación, e incluso la violencia de género.

\subsubsection{Chance Wayne}

Según el análisis del personaje como persona, a nivel iconográfico se observa que este joven tiene apenas 30 años y posee un aspecto fisico — complexión atlética, ojos azules y pelo rubio-, que puede abrirle las puertas de Hollywood, su principal objetivo. Además, su vestimenta realza su atractivo y es muy representativa del estilo de los años 60. En varias escenas que transcurren en la suite del hotel $-\mathrm{y}$ en actitud íntima con Alexandra-, aparece con el torso desnudo, algo que resulta bastante atrevido para el cine de la época. Chance es hablador, tiene un discurso persuasivo y sabe cómo utilizar las palabras para lograr su propósito y decirle a cada persona lo que necesita escuchar. Su transformación principal se produce justo al final, cuando recibe una paliza que desfigura su rostro. Con él se evidencia notablemente que «the male roles in Williams's plays, reaching a wider audience through various film versions, popularized a different kind of masculinity, offering images of desirable, vulnerable, and yet aggressive maleness that profoundly affected American ideas about gender» (Palmer, 1997: 231). 
En lo que respecta al ámbito psicológico, vive obsesionado con triunfar en Hollywood, donde se traslada, aunque confiesa que lo hace para poder ofrecer un futuro a Heavenly. Su carácter es impulsivo, pero también hedonista, por lo que su deseo de convertirse en una estrella de cine responde realmente a su egocentrismo. La relación que tiene con su novia es idealista, pues cree que ambos podrán disfrutar de una vida en común cuando triunfe como actor, algo que no se está produciendo. Además, ella representa para él la pureza y la perfección. Por otra parte, tiene una relación con Alexandra basada en la dominación. Cree que esta actriz lo ayudará a obtener buenos papeles en Hollywood, y esta es la razón por la que se convierte en su chófer, en su acompañante y, en definitiva, en su gigoló. Una de las personas que lo empujan a irse del pueblo es Boss Finley, quien considera que no es apropiado para su hija, lo acosa y hasta encarga que le den una dura paliza. Chance dejó a su madre enferma para buscar fortuna, y, finalmente, ella fallece estando él en Hollywood. La persona con la que establece un vínculo materno-filial es la tía de Heavenly, Nonnie, quien lo protege como a un hijo.

El pensamiento de este personaje es idealista. No obstante, al final «Chance believes his past stole his youth» (Smith-Howard y Heintzelman, 2005: 290). A pesar de su actitud seductora, así se refleja en sus sentimientos, marcados por el romanticismo que encarna Heavenly. El protagonista experimenta una abrupta evolución cuando Alexandra lo deja y descubre que ha perdido su última oportunidad para convertirse en una estrella, algo que empeora cuando a continuación le desfiguran la cara. Esto significa el final de su quimera. En el aspecto sociológico, Chance posee un origen humilde y un nivel cultural bajo, pero tiene interés en aprender para prosperar económicamente y ascender a nivel social. Sin duda, es bastante ambicioso y peca también de arrogante. En el ámbito de la sexualidad, es heterosexual, pero, olvidando sus sentimientos hacia Heavenly, recurre a la prostitución como medio para alcanzar su sueño.

En cuanto al análisis del personaje como rol, Chance es un fugitivo que se ve obligado a huir físicamente de su pueblo, aunque también huye de sí mismo. Motivado por triunfar en Hollywood tras haber fracasado en Broadway, no duda en abandonar a su madre y a su novia para seguir sus anhelos. Por ello, "he does not give up on his desires to become a star, but his chances wane as a result of the passing of time and his youth» (Smith-Howard y Heintzelman, 2005: 293). Sin embargo, no tiene suerte, y, mientras llega su oportunidad - se establece un guiño al significado de su nombre-, tiene que trabajar de socorrista y, después, como chófer de una actriz a la que sirve sexualmente. Su regreso a Saint Cloud implica recuperar a Heavenly para huir juntos a Hollywood y reintentar ser actor. Aunque se ve obligado a recurrir a la prostitución —algo inédito en el cine clásico, especialmente al tratarse de un hombre quien la ejerce-, está convencido de que esto lo llevará al estrellato. No obstante, la espera acentúa la inestabilidad de su condición de fugitivo. Por ello, vive en una huida constante. 
Dentro de la producción de Williams, Chance constituye una evolución con respecto a sus anteriores personajes masculinos. En los protagonistas de Un tranvía llamado deseo y de La gata sobre el tejado de zinc - Stanley Kowalski y Brick Pollit, interpretados por Marlon Brando y por Paul Newman-, se representaban dos temas muy polémicos para el código, la violencia de género y la homosexualidad, respectivamente. Además, ambos personajes se refugiaban en el alcohol, convirtiéndose en dos de los más complejos del autor. Partiendo de esta base, Chance no recurre a la bebida — que era la evasión habitual de los personajes masculinos del cine clásico-, sino al hachís y la prostitución, que eran aún más delicados para la censura. Estos aspectos no aparecieron conjuntamente, y en un personaje principal, hasta el estreno de Dulce pájaro de juventud. Aunque Williams había tratado la prostitución en Paolo DiLeo, el protagonista de La primavera romana de la señora Stone - encarnado por Warren Beatty-, la combinación con la drogadicción que se observa en Chance resultaba más rupturista. Sin duda, la prostitución masculina se abordaría de una forma abierta en Cowboy de medianoche (Midnight Cowboy, John Schlesinger, 1969), estrenada dos años después de la desaparición del Código Hays.

\subsubsection{Alexandra del Lago}

En el análisis como persona, se percibe a nivel iconográfico que Alexandra — conocida también como Princesa Kosmonopolis-, tiene unos 40 años y destaca por su seductora mirada y amplia sonrisa. Es una mujer atractiva que, además, posee una apariencia muy elegante, como indica el sofisticado vestuario que porta. Normalmente, emplea un tono de voz enfático, muestra un discurso elaborado y exagerado para hablar sobre sí misma y sus circunstancias, y habla con frivolidad, pues su vida en Hollywood también lo es. Sin embargo, cuando tiene que tratar cuestiones cruciales muestra una gran serenidad y sensatez que denotan su experiencia vital. La transformación principal que sufre afecta a su forma de expresarse, pues cuando se emociona habla de manera despótica, grita, ríe y llora. Así se aprecia cuando decide retomar su carrera tras recibir una llamada.

En el aspecto psicológico, se puede afirmar que es una víctima de sí misma. Aunque es una estrella de cine, su última película ha sido un fracaso y, por esta razón, se refugia en el alcohol, las drogas y el sexo. Ella tiene un carácter inestable y tiende a la depresión, pero, al mismo tiempo, muestra una gran fuerza y un considerable poder de decisión. Por lo tanto, «like many of Williams's heroic women, Alexandra has the strength to face an uncertain, potentially bleak future» (Clum, 1997: 144), de manera que no occulta su frágil situación. La relación que mantiene con Chance es interesada, ya que, mientras él espera convertirse en un buen actor gracias a su ayuda, ella solo lo quiere para su placer, incluído el sexual. Desde el principio, es consciente de las aspiraciones del protagonista, pero lo utiliza para superar su depresión. Finalmente, accede a firmarle un contrato que supondrá su de- 
but en Hollywood, pero luego le confiesa con dureza que no lo ayudará, de manera que le da falsas esperanzas sobre algo que para él es fundamental. Alexandra no mantiene una relación profunda con otros personajes, aunque, tras dejar a Chance, huye a Hollywood con Miss Lucy, la maltratada amante de Boss Finley.

En contraposición a la inestabilidad de su carácter, el pensamiento de la protagonista es realista. No obstante, sus sentimientos son ambivalentes, pues, por un lado, sabe cuál es su camino, pero, por otro, está emocionalmente desesperada. La actriz experimenta una importante evolución psicológica tras hablar por teléfono con el crítico de cine Walter Winchell, quien le confirma que su película ha sido un éxito. Esto le da confianza en sí misma y fortaleza para abandonar a Chance y volver a Hollywood, donde el mundo del cine la espera. En lo relativo a la sociología, pertenece a una clase cultural, económica y social alta debido a su estatus de estrella de cine. Ella es heterosexual y no tiene pareja estable, pero recurre a los servicios de un gigoló durante su depresión. En este sentido, recuerda a Karen Stone, «another aging actress who finds life in the arms of a beautiful young hustler» (Smith-Howard y Heintzelman, 2005: 295).

Con respecto al análisis del personaje como rol, Alexandra es víctima de su inseguridad personal y profesional, y este es el origen de su papel fugitivo. Además, le horroriza la idea de envejecer y piensa que es mayor para verse atractiva en la gran pantalla. Aunque es una afamada actriz, huye de Los Ángeles tras el supuesto fracaso de su último filme, así que, motivada por este pánico contrata a Chance para evadirse de su crisis. Se siente atraída por la belleza y la juventud de este chico, pues es consciente de que la suya se está escapando. Un aspecto que indica su rol de fugitiva es la dificultad para adaptarse al entorno en el que se encuentra, situación que la lleva a vivir ensimismada y a buscar refugio en el sexo y en las drogas. De hecho, aparece fumando hachís y pidiéndole a su amante hacer el amor tras consumir juntos. Esto resulta bastante novedoso para el cine del momento, pues, normalmente, los protagonistas no aparecían consumiendo drogas - algo que cambió con El hombre del brazo de oro (The Man With the Golden Arm, Otto Preminger, 1955)-, y no solía ser la mujer quien llevara la iniciativa. Esta actitud revela que Alexandra es una mujer independiente y ajena a los convencionalismos.

La protagonista es uno de los personajes femeninos más dramáticos de Williams, quien unió en ella varias de las constantes de su obra, como el miedo y el sexo. Ambos temas marcaban la trágica existencia de la protagonista de Un tranvía llamado deseo, Blanche DuBois - interpretada por Vivien Leigh-, pero de una manera totalmente dramática. A diferencia de ella, el sexo supone para Alexandra una liberación que no le provoca una tortura emocional, como sí le ocurría a Blanche. Así lo demuestra al reconocer que se siente renacida, cuando previamente le había exigido a Chance mantener relaciones. Por otra parte, no era habitual que un personaje femenino tomara drogas en la gran pantalla, y menos sin ocultarlo y sin arrepentimiento. 
Esto evidencia el carácter rupturista de este personaje. En cuanto al sexo, al año siguiente del cese del código se estrenó La mujer maldita, donde Flora Goforth —encarnada por Elizabeth Taylor-, admitía con una mirada de deseo que tenía necesidad de compañía masculina.

\subsubsection{Heavenly Finley}

Según el análisis del personaje como persona, a nivel iconográfico se advierte que esta joven tiene unos 20 años y una imagen que está en perfecta armonía con el significado de su nombre. Heavenly, que es rubia, muy blanca, tiene los ojos azules y una delgada complexión, posee una apariencia virginal, como se percibe especialmente en su clásico y recatado vestuario blanco, que suele utilizar por orden de su padre, el ultraconservador político Boss Finley, quien controla Saint Cloud como un cacique. Ella no es habladora y parece tímida, pero su discurso está marcado por la honestidad. Por ello, cuando habla con su progenitor lo hace con total sinceridad, y hasta con resentimiento. La principal transformación que sufre se produce al final, cuando empieza a ponerse ropa de colores fuertes, e incluso negro, y se enfrenta a Boss con convencimiento.

A nivel psicológico, este personaje tiene un carácter estable y muy tranquilo a pesar de la dificil situación personal y familiar que atraviesa. Está totalmente manipulada por su su padre, quien explota su aspecto virginal para sus propósitos políticos, vinculados a las ideas de pureza, Dios y la Bilia; una pantalla con la que intenta tapar la violencia y la corrupción con que gobierna (Smith-Howard y Heintzelman, 2005), controlando incluso los medios de comunicación. La relación que la joven tiene con él es de sumisión, y así se demuestra cuando él la obligó a abortar contra su voluntad porque no estaba casada, ya que esto suponía una mala imagen para su campaña política. Por otra parte, mantiene una relación sentimental con Chance basada en la espera, e intenta convencerse de que él va a volver para poder huir juntos, aunque va percibiendo que esto se desvanece. La única persona que la apoya y la ayuda con su novio es tía Nonnie, quien representa la figura de su madre. Ambas tienen una relación estrecha y de gran complicidad.

Los pensamientos de Heavenly se encuentran entre el realismo y el idealismo debido a la dicotomía emocional en la que vive, y sus sentimientos son románticos al ser Chance el motor que la empuja a seguir. En este sentido, su padre planea su boda con George Scudder, el médico que le practicó el aborto, al ser el único ajeno a la familia que sabe que no es virgen, pero ella se opone. Heavenly es distinta de Alexandra porque lucha para que Chance salga de un mundo corrupto en el que nunca debió entrar. Clum indica que «the two women never meet, but offer the two sexual and emotional possibilities Chance experiences in the play» (1997: 140). Finalmente, sufre una notabe evolución cuando, tras ser humillada en el mitin 
de Boss y ver la paliza de Chance, se rebela ante su padre y huye con su novio. En el aspecto sociológico, pertenece a una clase social y económica alta debido al estatus político de Boss, pero posee un nivel cultural medio. Heavenly es heterosexual y concibe el sexo como un acto de amor.

Con respecto al análisis del personaje como rol, la joven es una fugitiva que vive en una mansión sureña de columnas blancas, que representa una prisión, bajo el control de dos guardaespaldas contratados por su padre. Al quedarse embarazada, la obligan a abortar y decide no contárselo a Chance para no perjudicar su carrera. Este silencio va unido a su carácter de chica buena (Guarinos, 2007), pues es sumisa y solo desea que Chance la recoja para irse de Saint Cloud, pero realmente es infeliz. Motivada por la necesidad de huir de su progenitor dominante, termina fugándose con su novio, y, aunque es el único personaje de la película que logra su objetivo, sufre mucho para ello. Esto lo convierte en una fugitiva a nivel fisico, mientras que durante su amarga existencia en el caserón lo es a nivel mental por refugiarse en sus recuerdos. El aborto aparece tratado como algo clandestino que se ejecuta cuando una mujer no está casada, así que está vinculado al mantenimiento de un orden familiar, moral y religioso, como defiende Boss. Este filme es el primero que abordó este prohibido aspecto durante la crisis del código.

En la obra de Williams, Heavenly es uno de los personajes que más sufre la represión sexual. Tanto para su novio — quien sabe lo que es prostituirse-, como para su progenitor - quien defiende la pureza a ultranza-, encarna un modelo de virginidad que le pesa cada vez más. Así, las expectativas que tienen en ella van mermando su carácter, sobre todo tras abortar. Este tema estaba prohibido por el peso católico del código, pero a finales de los años 50 algunos melodramas empezaron a tratarlo de forma trágica, tanto para quien lo sufría como para su entorno. Así se evidencia en Selena Cross —encarnada por Hope Lange-, uno de los personajes secundarios de Vidas borrascosas (Peyton Place, Mark Robson, 1957) —adaptación de la novela de Grace Metalious-, quien, además, asesinaba a su violador. No obstante, el aborto voluntario tardaría décadas en tratarse en el cine.

\section{Conclusiones}

Las adaptaciones de Tennessee Williams contribuyeron al aperturismo temático del cine clásico. Temas como la ninfomanía, la homosexualidad, la prostitución masculina o el aborto aparecieron por primera vez en el celuloide a través de sus complejos personajes, causando un gran impacto en el Hollywood posterior a la II Guerra Mundial. El Código Hays acabó en 1934 con el tratamiento de temas considerados amorales, de modo que, hasta que no se estrenaron los filmes basados en los textos del autor, a partir de 1950, la libertad temática no se fue recuperando. No obstante, las películas debían contar con el sello de aprobación de la PCA 
para estrenarse, así que había que evitar los aspectos que el código prohibía. Según esta premisa, las obras del escritor no podían llevarse al cine, pero el interés de diversos productores y cineastas de recuperar al público favoreció las adaptaciones, eso sí, con ciertos cambios para superar la censura. Además, estos títulos contribuyeron al desarrollo del melodrama, agregando atmósferas opresivas, conflictos de tipo psicológico y sexual — presentes en la sociedad, pero ocultos por causas morales-, y personajes víctimas de circunstancias desfavorables. Estas películas posibilitaron la disolución del código en 1967 y reflejaron «the growth in Hollywood of an adult cinema to which playwright Tennessee Williams made such important contributions, with $A$ Streetcar Named Desire in effect inaugurating a tradition that would endure until the end of the studio system in the early 1970s» (Palmer, 2014: 123).

El universo sureño del dramaturgo, marcado por su origen, las tradiciones y su refugio artístico y vital en Nueva Orleans, explica su tendencia por abordar cuestiones como el declive del espacio heredero del Old South - donde transcurren la mayoría de sus textos-, el miedo de unos personajes fugitivos y el sexo como vía de liberación en un entorno tan conservador como opresor. Así se plasma en una de sus principales adaptaciones, y más crítica con la puritana, clasista y corrupta sociedad sureña de principios de los 60, Dulce pájaro de juventud. Aquí, sus tres protagonistas ejercen el rol de fugitivos, por lo que se trata del filme de Williams con más personajes de este tipo. En este sentido, son fugitivos a nivel psicológico, al sufrir la incomprensión social, familiar o profesional, o situaciones de abuso - incluso sexual-, y precisan refugiarse mentalmente de su violento ambiente, pero también a nivel físico, pues, a raíz de esta situación, toman conciencia y deciden actuar, normalmente huyendo de donde viven. Sin embargo, en esta huida hacia adelante no siempre encuentran lo que anhelaban, frustrándose aún más y sintiéndose fracasados. Por ello, recaen en varias adicciones para evadirse. A veces se refugian en el sexo o en las drogas al ser incapaces de enfrentarse a sus problemas, y esto los conduce a una espiral de autodestrucción, pero otras veces consiguen superarlos.

En Dulce pájaro de juventud, Chance, Alexandra y Heavenly —cuyos nombres reflejan sus personalidades-, encarnan ambos niveles. Además, están marcados por el miedo al fracaso, la soledad y la incomprensión - aspectos comunes a los fugitivos williamsianos - y esta combinación favorece la aparición de diversas adicciones para tratar de superar su situación. En primer lugar, Alexandra recurre a las drogas para superar el fracaso de su última película, poniendo de relieve los vicios y debilidades de un Hollywood cruel con sus estrellas y cada vez más desmitificado. Chance ejerce la prostitución como medio para promocionar en el cine, pues sabe que con su belleza y su juventud puede alcanzar este objetivo en un mundo tan deslumbrante como perverso. Por último, Heavenly, cuyo padre la obliga a abortar porque está soltera, y esto perjudica su conservadora carrera política, evidencia el conservadurismo de una América profunda que no duda en borrar por completo lo que considera corrupto, aunque esto suponga una total hipocresía. No obstante, mientras que «Chance and the 
Princess are very similar characters. They are both battling life and time for a chance to remain among the beautiful people» (Smith-Howard y Heintzelman, 2005: 293), Heavenly es más consciente de la imposibilidad de recuperar el tiempo. Aunque finalmente los tres huyen de sus problemas, ninguno logra recuperarse de lo que irremediablemente han perdido: los años de su juventud. Por ello, son personajes representativos del complejo universo del dramaturgo y, también, de los antihéroes que protagonizaron el cine de Hollywood a partir de los 50, quienes, con el tratamiento de temas próximos a la sociedad, determinaron la crisis del código.

\section{Referencias bibliográficas}

Berman, P.S. (producer) \& Brooks, R. (director) (1962). Sweet Bird of Youth. USA: Metro Goldwyn Mayer.

Black, G.D. (1998). Hollywood censurado. Madrid: Cambridge University Press.

Casas, Q. \& Iriarte, A.C. (2009): Richard Brooks. San Sebastián-Madrid: Festival Internacional de cine de San Sebastián/ Filmoteca Española.

Casetti, F. \& Di Chio, F. (2007). Cómo analizar un film. Barcelona: Paidós.

Clum, J.M. (1997). "The sacrificial stud and the fugitive female in Suddenly, Last Summer, Orpheus Descending and Sweet Bird of Youth». In Roudané, Matthew C. (ed.), The Cambridge Companion to Tennessee Williams. Cambridge: Cambridge University Press, pp. 128-146.

Devlin, A.J. y Tischler, N.M. (2004). The Selected Letters of Tennessee Williams. Volume II. 1945-1957. New York: New Directions.

Durán Manso, V. (2011). La complejidad psicológica de los personajes de Tennessee Williams. Frame, núm. 7, pp. 38-76. Recuperado de: http://fama2.us.es/fco/frame/ frame7/estudios/1.3.pdf

Durán Manso, V. (2015). El dramatismo de los personajes de Tennessee Williams enel melodrama de Pedro Almodóvar: Tacones lejanos. En: Camarero, Enma y Marcos María (coords.) III Congreso Internacional Historia, Literatura y Arte en el Cine en español y portugués. Hibridaciones, transformaciones y nuevos espacios narrativos. Salamanca: Centro de Estudios Brasileños. Universidad de Salamanca. Tomo I, pp. 678-691.

Frome, S. (2001). The Actors Studio. A History. Jefferson: Mcfarland \& Company.

Guarinos, V. (2007). «Mujeres en proyección. La mujer en el cine. Teoría fílmica Feminista». En LOSCERTALES, Felicidad y NÚÑEZ, Trinidad (coords.) La mirada de las mujeres en la sociedad de la información. Madrid: Siranda, pp. 91-112.

Holditch, K. \& Freeman Leavitt, R. (2010). Tennessee Williams and the South. Jackson: University Press of Mississippi.

Hooper, M.S.D. (2014). «Pedro Almodovar's 'Homage' to Tennessee Williams». In Back, John S. (ed.) Tennessee Williams and Europe. Interculrural Encounters, Transatlantic Exanges. Amsterdam: Rodopi, pp. 347-367. 
Paller, M. (2014). «Their Date with Each Other from the Beginning: Tennessee Williams and Harold Pinter». In Back, John S. (ed.), Tennessee Williams and Europe. Interculrural Encounters, Transatlantic Exanges. Amsterdam: Rodopi, pp. 281-297.

Palmer, R. Barton (1997). «Hollywood in crisis: Tennessee Williams and the evolution of the adult film». In Roudané, Matthew C. (ed.), The Cambridge Companion to Tennessee Williams. Cambridge: Cambridge University Press, pp. 204-231.

Palmer, R. Barton \& Bray, R. (2009). Hollywood's Tennessee. The Williams Films and Postwar America. Austin: University of Texas Press.

Palmer, R. Barton (2014). "The View from Here and Abroad: Tennessee Williams and 1950s Hollywood Cinema». In Back, John S. (ed.) Tennessee Williams and Europe. Interculrural Encounters, Transatlantic Exanges. Amsterdam: Rodopi, pp. 111-130.

Phillips, G.D. (1980). The Films of Tennessee Williams. Philadelphia: Art Alliance.

Rodríguez de Austria Giménez de Aragón, A. (2015). «El código de producción de Hollywood (1930-1966): censura, marcos (frames) y hegemonía». ZER. Revista de Estudios en Comunicación, Vol. 20, núm. 39, pp. 177-193. Recuperado de: https://www. ehu.eus/ojs/index.php/Zer/article/view/15533

Smith-Howard, A. \& Heintzelman, G. (2005). Critical Companion to Tennessee Williams. A literary Reference to His Life and Work. New York: Checkmark.

Spoto, D. (1985): The Kindness of Strangers. The Life of Tennessee Williams. Boston: Da Capo Press.

Steen, M. (1969). A Look at Tennessee Williams. New York: Hawthorn.

Williams, T. (2009): Sweet Bird of Youth and Other Plays. Period of Adjustment and The Night of the Iguana. London: Penguin.

Williams, T. (2008). Memorias. Barcelona: Ediciones B.

Yacowar, M. (1977): Tennessee Williams \& Film. New York: Frederick Ungar. 